\title{
Chromosomal imbalances in four new uterine cervix carcinoma derived cell lines
}

\author{
Alfredo Hidalgo ${ }^{1}$, Alberto Monroy ${ }^{2}$, Rosa Ma Arana ${ }^{3}$, Lucía Taja ${ }^{4}$, \\ Guelaguetza Vázquez ${ }^{1}$ and Mauricio Salcedo*1
}

Address: ${ }^{1}$ Laboratorio de Oncología Genómica, Unidad de Investigación Médica en Enfermedades Oncológicas, Hospital de Oncología, Centro Médico Nacional Siglo XXI-IMSS, Mexico, ²Laboratorio de Diferenciación Celular y Cáncer, FES Zaragoza, UNAM, Mexico, ${ }^{3}$ Servicio de Genética, Hospital General de México, SS, Mexico and ${ }^{4}$ División de Investigación Básica, Instituto Nacional de Cancerología, SS, Mexico

Email: Alfredo Hidalgo - alfhm@yahoo.com; Alberto Monroy - albertomon@yahoo.com; Rosa Ma Arana - aranat@prodigy.net.mx; Lucía Taja - Itaja_chayeb@yahoo.com; Guelaguetza Vázquez - guelav@yahoo.com; Mauricio Salcedo* - maosal89@yahoo.com

* Corresponding author

Published: 20 March 2003

BMC Cancer 2003, 3:8
Received: 20 January 2003

Accepted: 20 March 2003

This article is available from: http://www.biomedcentral.com/l47/-2407/3/8

(C) 2003 Hidalgo et al; licensee BioMed Central Ltd. This is an Open Access article: verbatim copying and redistribution of this article are permitted in all media for any purpose, provided this notice is preserved along with the article's original URL.

\begin{abstract}
Background: Uterine cervix carcinoma is the second most common female malignancy worldwide and a major health problem in Mexico, representing the primary cause of death among the Mexican female population. High risk human papillomavirus (HPV) infection is considered to be the most important risk factor for the development of this tumor and cervical carcinoma derived cell lines are very useful models for the study of viral carcinogenesis. Comparative Genomic Hybridization (CGH) experiments have detected a specific pattern of chromosomal imbalances during cervical cancer progression, indicating chromosomal regions that might contain genes that are important for cervical transformation.
\end{abstract}

Methods: We performed HPV detection and CGH analysis in order to initiate the genomic characterization of four recently established cervical carcinoma derived cell lines from Mexican patients.

Results: All the cell lines were HPVI8 positive. The most prevalent imbalances in the cell lines were gains in chromosomes Iq23-q32, 3qII.2-q|3.I, 3q22-q26.I, 5p|5.I-plI.2, this alteration present as a high copy number amplification in three of the cell lines, 7p I5-p I3, 7q2I, 7q3।, I Iq2I, and $12 q \mid 2$, and losses in $2 q 35$-qter, $4 p 16,6 q 26$-qter, $9 q 34$ and $19 q \mid 3.2$-qter.

Conclusions: Analysis of our present findings and previously reported data suggest that gains at $|q 3|-q 32$ and $7 p|3-p| 4$, as well as losses at 6q26-q27 are alterations that might be unique for HPVI8 positive cases. These chromosomal regions, as well as regions with high copy number amplifications, coincide with known fragile sites and known HPV integration sites. The general pattern of chromosomal imbalances detected in the cells resembled that found in invasive cervical tumors, suggesting that the cells represent good models for the study of cervical carcinoma.

\section{Background}

Cervical carcinoma stands as the first cause of death among the Mexican female population with 14 deaths per 100,000 women with 15 years old or more, representing
$34.2 \%$ of all new female cancer cases reported [1]. High risk human papillomavirus (HPV) infection is considered to be the most important risk factor associated with the 
Table I: Chromosomal imbalances detected in hpv 18 positive cell lines

\begin{tabular}{|c|c|c|c|c|}
\hline Cell line & Tumor stage & DNA Losses & DNA Gains & Total \\
\hline CALO & II-B & $\begin{array}{c}\text { Ipter-p32, 2q35-qter, 4pter-p I5.2, 4q32-qter, 5q33- } \\
\text { qter, 6q24-qter, 8pter-p22, 8q24.2-qter, 9q32-qter, } \\
\text { IIqI2, I 2pI3, I 2q22-qter, I3qI2, I5qII.2-qI2, } \\
\text { I6p, I 6q22-qter, I7, I8qIII, 19, 20, 2I, 22. } \\
\text { Total:2I }\end{array}$ & $\begin{array}{l}I p 3 I-p|2, I q 22-q 3 I, 2 p| 5,2 q 2 I-q 32,3 p 22, \\
3 q I I .2-q 26.3,4 q 26-q 3 I .2,5 p, 5 q 1 I .2-q 23,6 q 22, \\
7 p|5-p| 2,7 q 2 I-q 3 I, 9 p 23-p 2 I, I|q| 4-q 22, \\
I 2 p|I .2, I 2 q| 5-q 2 I, I 3 q 2 I-q 3 I, I 8 q \mid 2 \text {. Total: I8 }\end{array}$ & 39 \\
\hline VIPA & $I I-A$ & 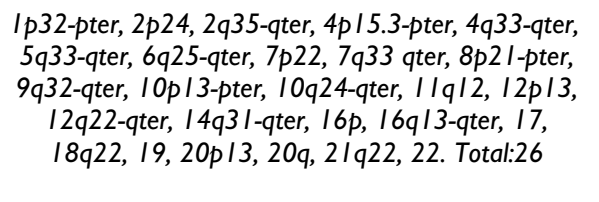 & 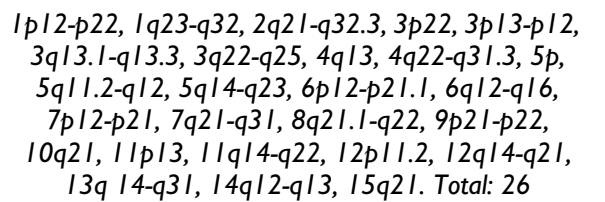 & 52 \\
\hline INBL & $I V-A$ & $\begin{array}{c}\text { 2q34-qter, 4p, 4q32-qter, 6q24-qter, 8p22, I3q12, } \\
\text { I8p2I-pter, 19p/3.2-pter. Total: } 8\end{array}$ & 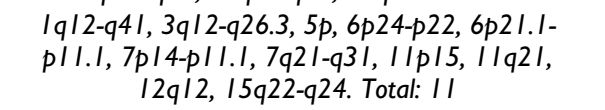 & 19 \\
\hline \multirow[t]{2}{*}{ ROVA } & $I V-A$ & $\begin{array}{c}\text { Ip35-pter, 2p25, 2q35-qter, 3q29-qter, 4p I6, 5q35, } \\
\text { 6q26-qter, 7p22, 8p23, 8q24.I-qter, 9q33-qter, } \\
\text { I0q26, I 2p I3, I 2q24.I-qter, I 6p, I 6q22-qter, } \\
\text { I 7p/2-pter, I 7q23-qter, I 8q22-qter, I 9, 20q13. } \\
\text { qter, 2 I q22, 22q. Total: } 23\end{array}$ & 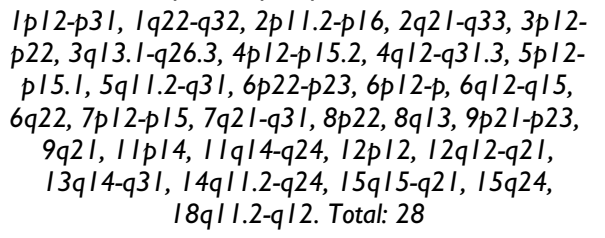 & 51 \\
\hline & Average & 19.5 & 20.7 & ANCA: 40.2 \\
\hline
\end{tabular}

All tumors were diagnosed as squamous cell carcinomas. ANCA: Average Number of Chromosomal Aberrations, obtained dividing the total number of observed alterations between the total number of cases.

development of this tumor, and is present in $99.7 \%$ of the invasive cervical tumors worldwide [2].

Comparative Genomic Hybridization (CGH) is a method employed in cancer genomics that allows the detection of DNA gains or losses at the genome level in a single hybridization experiment, indicating cytogenetic regions that might be involved in the transformation process. CGH has detected a specific pattern of chromosomal imbalances associated with particular stages of cervical transformation, and with different biological behaviors [3-10]. In this paper, we evaluated the presence of HPV DNA and analyzed the pattern of chromosomal imbalances using CGH in four cell lines established from tumor explants of Mexican patients. The establishment and research use of two of these cell lines has been previously reported $[11,12]$. Further genomic characterization of these lines will open new possibilities for understanding cervical carcinoma, since the coincidence between the chromosomal imbalances present in these cell lines and patterns found in cervical tumors indicate that they are good models for the study of cervical cancer.

\section{Methods}

The cell lines were established from stages IIA and IVA squamous cell cervical carcinoma explants from Mexican females (Table 1) at the National University of Mexico, as previously described $[11,12]$. Cell lines were designated CALO, INBL, VIPA and ROVA.

HPV detection was done using the $\mathrm{L} 1$ consensus primers MY09/MY11. After denaturation at $94^{\circ} \mathrm{C}$ for 5 minutes, $100 \mathrm{ng}$ of DNA were subjected to 40 cycles of $94^{\circ} \mathrm{C}$ for 1 $\min , 55^{\circ} \mathrm{C}$ for $2 \mathrm{~min}$ and $73^{\circ} \mathrm{C}$ for $3 \mathrm{~min}$, with a final extension step of $7 \mathrm{~min}$ at $72^{\circ} \mathrm{C}$. The amplicon was labeled using the Big Dye kit (Applied Biosystems, Foster City, CA) and sequenced with an ABI 373 automated sequencer. BLAST sequence comparison was done in order to know the HPV type.

All CGH procedures were performed using reagents and kits from Vysis Inc. (Downers Grove, IL), following the manufacturer's instructions. Cell line DNA was labeled using the CGH nick translation kit, and the hybridization mixture was prepared according to the CGH reagent kit, consisting of $200 \mathrm{ng}$ of spectrum-green labeled cell line DNA, $100 \mathrm{ng}$ of spectrum-red labeled normal male reference DNA and $20 \mu \mathrm{g}$ of human Cot- 1 DNA. Hybridization was performed over 3 days at $37^{\circ} \mathrm{C}$ on normal male metaphase spreads (Vysis, Downers Grove, IL).

Digital images were collected using the Smart Capture (Vysis) software with a charged coupled device camera mounted on an epifluorescence microscope. An average of 15 metaphases per case were analysed using the Vysis 
CGH software using a $>1.2$ ratio threshold for detecting DNA gains and $<0.8$ for losses, these thresholds were chosen based on previous normal VS. normal hybridizations. Sex chromosomes and heterochromatic areas (centromeric and paracentromeric regions of chromosomes 1, 9, 16, $\mathrm{p}$ arms of acrocentric chromosomes) were excluded from the analysis. A "reverse painting" experiment was used as a control for the CGH results. CGH data from the cell lines is available at the NCI and NCBI Spectral Karyotyping (SKI) and CGH Database http://www.ncbi.nlm.nih.gov/ sky/skyweb.cgi.

\section{Results and Discussion}

HPV DNA was detected in all the cell lines. Sequence analysis identified HPV18 in all the samples. All the cell lines presented chromosomal imbalances. A line summary ideogram of the chromosomal imbalances in the cell lines is presented in Figure 1. A complete description of the imbalances detected in each cell line is presented in Table 1. On the average, 19.5 DNA losses and 20.7 gains were detected in the samples, with an average number of chromosomal aberrations of 40.2 alterations per case, ranging from 52 alterations in VIPA to 19 alterations in INBL. The most prevalent imbalances were gains in chromosomes 1q23-q32, 3q11.2-q13.1, 3q22-q26.1, 5p15.1-p11.2. This alteration is present as a high copy number amplification in three of the cell lines, 7p15-p13, 7q21, 7q31, 11q21, and 12q12, and losses in 2q35-qter, 4p16, 6q26-qter, 9q34 and 19q13.2-qter. Comparison between chromosomal imbalances in these cell lines and those found in cervical tumors; indicate the presence of common genetic alterations, suggesting that they represent their tissue of origin. These common regions include gains in 3q22q26.2 and 5p, and losses on 2q35-qter, 4q32-qter and $18 \mathrm{q}$. Some of these alterations have been detected in early stages of cervical transformation and are conserved in advanced tumors or have been associated with the presence of metastases and with a worse clinical behavior $[6,7,10]$, making the cells good models for the study of genes involved in the maintenance of the transformed phenotype. Compared with the imbalances previously found on HPV18 positive cases [9], there is coincidence for the DNA gains at 1q31-q32, 3q22-q26.3, 5p14 and 7p13-p14, as well as in DNA losses at 2q33-qter and 6q26-q27. Differences among the cell lines and data from invasive cervical tumors were also found. For example, we did not find deletions of $3 p$ or $11 q$ regions in the cell lines. This situation might be explained by the enrichment or selection of a particular cell clone during the cell line establishment.

A common observation in uterine cervix carcinomas is the integration of HPV DNA into the cellular genome. However, the consequences of this integration event are only poorly understood. Differences in the frequency of HPV18 and HPV16 integration have been detected, 72\% of the HPV16 tumors presented viral integration, while HPV18 positive tumors had viral integration in $100 \%$ of the cases $[13,14]$. This is a possible explanation for the observed HPV18 incidence in the studied cell lines, since the integration event might represent a growth advantage for the cell in culture. Analysis of our present findings and previously reported data suggest that gains at 1q31-q32 and 7p13-p14, as well as losses at 6q26-q27 are alterations that are unique for HPV18 positive cases. HPV integration at the 1q31-q32 has been found in nasal epithelial cells immortalized with HPV16 DNA and also contains the short tandem repeat region F13B [15]. The NEK7 (NIMA (never in mitosis gene a)-related kinase 7, 1q31.3) gene is located in this region and plays an important role in the control of mitosis initiation [16]. The role of this gene in human cancer has not been explored. Regarding the 7p15-p13 region, a lymphocyte fragile site has been detected at 7p13, high copy number amplification of this region was also found by us in primary cervical carcinomas [9] and gain of 7p was also found in HPV transfected cells during the immortalization process [4]. The PE5L gene, (7p13-p14) presents a sequence homology with the HPV18 E5 gene, making this gene a possible target for recombination and viral integration [17]. However, alignment of the PE5L sequence against the November 2002 freeze of the Human Genome working draft, showed the best matching score on 7p11.2 (not shown). The public availability of viral-cellular fusion transcripts or DNA sequences, combined with data from the human genome, will certainly help to better define areas of viral integration for further investigation.

The lost cytogenetic region $6 \mathrm{q} 26$ comprises the fragile site FRA6E, the third most frequently observed common fragile site. Deletion of the 6q26-q27 region has been found in approximately $44 \%$ of all tumor types analyzed by CGH [18], and in cervical carcinoma loss of heterozigosity was found $39 \%$ of the cases [19]. An interesting gene located in this region is the mitogen-activated protein kinase kinase kinase 4 (MAP3K4), a major mediator of environmental stresses that activate the CSBP2 MAPK pathway, which, in turn, regulates the expression of TNF and several cytokines, and controls the initiation of the G2/M checkpoint after UV radiation [20].

We also found high copy number amplifications in regions $7 \mathrm{q} 21,7 \mathrm{q} 31,11 \mathrm{q} 21$ and $11 \mathrm{q} 12$. Region $7 \mathrm{q} 21$ contains the rare, folic acid type FRA7E fragile site and a cellular-HPV fusion transcript has been detected at this area, with no sequence match to a known gene [21]. 7q31 has been reported to be the site of a chromosomal breakpoint in cervical carcinoma cell lines [22] and contains the c-Met oncogene, whose over-expression has been correlated to the diameter of the primary tumor, deep cervical stromal invasion, presence of metastatic lymph node and 

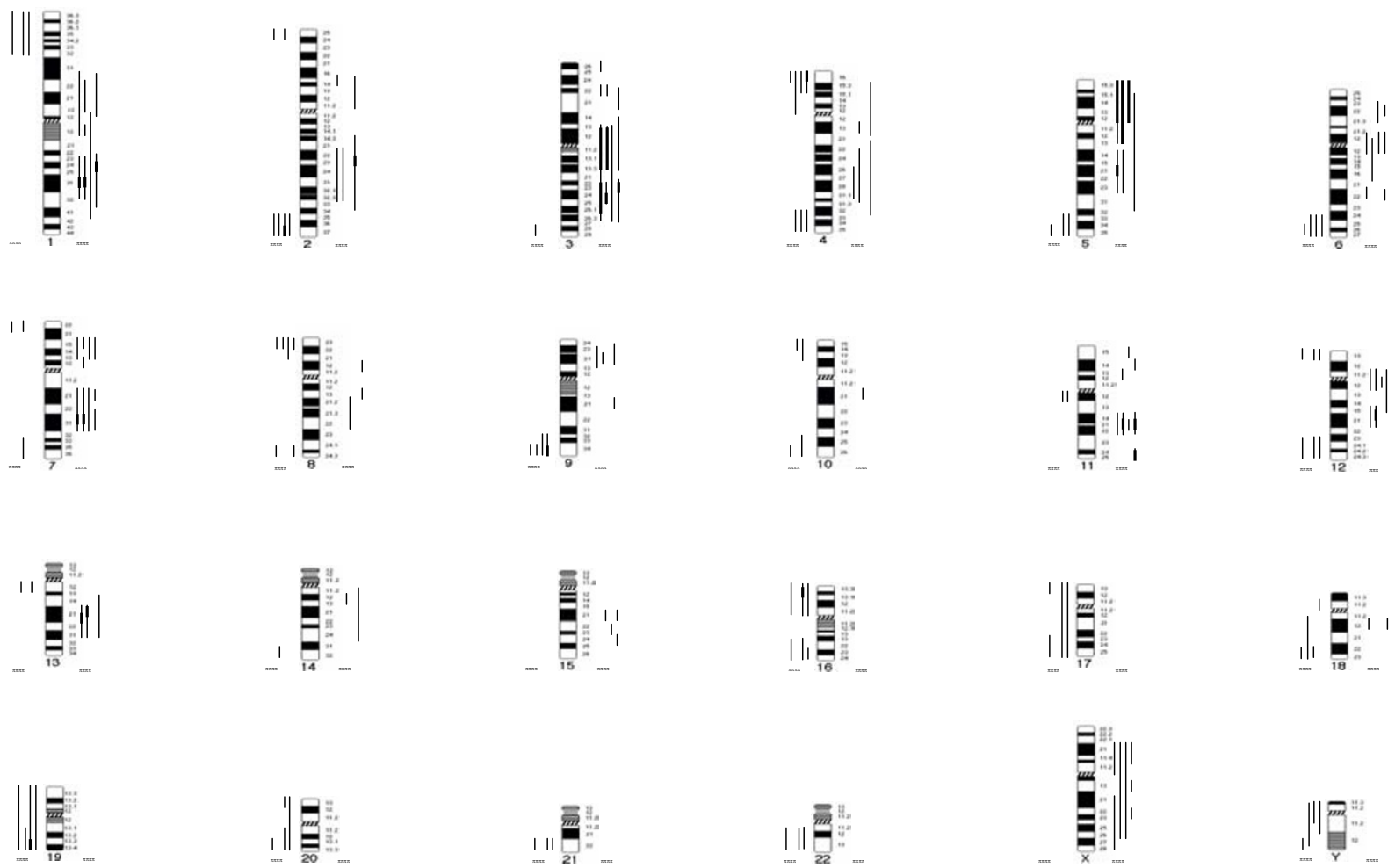

\section{Figure I}

CGH ideograms of the genetic imbalances detected in the cell lines. The lines at the right of the chromosome ideogram represent DNA gains, lines at the left, DNA losses. Thick lines represent high copy number amplifications or multi copy deletions (ratio > I.4 or <0.6). The mark closest to the ideogram represents the cell lines CALO, followed by VIPA, INBL and ROVA.

number of metastatic lymph nodes [23]. The 11q21-q22 region was also found in our cell lines, this region has been found amplified in some cervical carcinoma cell lines and over-expression of the cIAP1 gene, an apoptosis inhibitor and possible target of the amplification, was related to a poorer overall survival and local recurrence-free survival in cervical carcinoma [24].

It is interesting to notice that almost all of the possible HPV18 related sites of chromosomal imbalance, as well as the regions with high copy number amplifications in our cell lines correspond to the location of fragile sites in the human genome. Since HPV integration preferentially seems to target these kind of fragile sites, it is possible that HPV18 is integrated into these altered chromosomal regions in our cell lines. Recently, a comprehensive charac- terization of cervical cancer cell lines gave very useful information about specific chromosomal alterations, DNA gains, losses and clusters of chromosome breakpoints in cervical cancer cell lines and their relation to HPV presence and integration [24]. Currently, such a characterization of our newly established cell lines is being carried out.

\section{Conclusions}

High throughput genetic analysis often require vast amounts of tissue that sometimes is not available, making the cell lines the model of choice to overcome this problem. Here, we report the presence of HPV18 and the pattern of chromosomal imbalances detected in four newly established uterine cervix carcinoma derived cell lines. The pattern of genetic imbalances in these cell lines sug- 
gest that they represent good models for cervical carcinoma and HPV18 infection, providing another useful cellular model for the discovery and functional analysis of genomic alterations involved in cervical cancer when this viral type is present.

\section{List of abbreviations}

CGH: Comparative Genomic Hybridization. HPV: Human Papilloma virus. SKI: Spectral karyotyping

\section{Competing interests}

None declared.

\section{Authors contributions}

AH: Carried out the CGH experiments and data analyses, writing and designing paper and figures. AM: Cell line establishment. RMA: CGH metaphase analyses. LT: Cell cultures and DNA extraction. GV: HPV typing. MS: Design and coordination of the study.

\section{Acknowledgments}

This work was partially funded by grants from the CONACyT (34686-M) and IMSS (FP-200I/043), AH, GV and LT are recipients of a CONACyT scholarship and $A H$ and GV receive a DGEP-UNAM and IMSS scholarships.

\section{References}

I. Mexican Ministry of Health Registro Histopatológico de Neoplasias Malignas, Compendio de mortalidad y morbilidad. Secretaría de Salud, México 1998.

2. Walboomers J, Jacobs M, Manos M, Bosch X, Kummer A, Shah K, Snijders P, Peto J, Meijer $C$ and Muñoz N Human Papilloma Virus is a necessary cause of invasive cervical cancer worldwide. J Pathol 1999, 189:12-19

3. Heselmeyer K, Schröck E, Du Manoir S, Blegen H, Shah K, Steinbeck $R$, Auer $G$ and Ried T Gain of chromosome 3q defines the transition from severe dysplasia to invasive carcinoma of the uterine cervix. Proc Natl Acad Sci USA 1996, 93:479-484

4. Solinas-Toldo S, Dürst M and Lichter P Specific chromosomal imbalances in human papillomavirus transfected cells during progression toward immortality. Proc Natl Acad Sci USA 1997, 94:3854-3859

5. Kirchhoff M, Rose H, Laub B, Maahr J, Gerdes T, Lundsteen C, Bryndorf T, Kryger N, Christensen L, Aage S and Philip J Comparative genomic hybridization reveals a recurrent pattern of chromosomal aberrations in severe dysplasia/carcinoma in situ of the cervix and advanced-stage cervical carcinoma. Genes Chrom Cancer 1999, 24: 144-150

6. Allen D, White D, Hutchins A, Scurry J, Tabrizi S, Garland S and Armes Progressive genetic aberrations detected by comparative genomic hybridization in squamous cell cervical cancer. Br J Cancer 2000, 83:1659-1663

7. Dellas A, Torhorst J, Jiang F, Proffit J, Schultheiss E, Hotzgreve W, Sauter G, Mihatsch M and Moch H Prognostic value of genomic alterations in invasive cervical squamous cell carcinoma of clinical stage IB detected by comparative genomic hybridization. Cancer Res 1999, 59:3475-3479

8. Kirchhoff M, Rose H, Petersen B, Maahr J, gerdes T, Philip J and Lundsteen $C$ Comparative genomic hybridization reveals non-random chromosomal aberrations in early pre-invasive cervical lesions. Cancer Genet Cytogenet 200 I, I 29:47-5 I

9. Hidalgo A, Schewe C, Petersen S, Salcedo M, Gariglio P, Schlüns K, Dietel $M$ and Petersen I Human papilloma virus status and chromosomal imbalances in primary cervical carcinomas and tumor cell lines. Eur J Cancer 2000, 36:542-548

10. Umayahara K, Numa F, Suehiro Y, Sakata A, Nawata S, Ogata H, Suminami $Y$, Sakamoto M, Sasaki K and Kato H Comparative Genomic hybridization detects genetic alterations during early stages of cervical cancer progression. Genes Chromosomes Cancer 2002, 33:98- 102

II. Caceres-Cortes J, Alvarado-Moreno J, Waga K, Rangel-Corona R, Monroy-Garcia A, Rocha-Zabaleta L, Urdiales-Ramos J, Weiss-Stei$\operatorname{der}$ B, Haman A, Hugo P, Brousseau R and Hoang T Implication of tyrosine kinase receptor and steel factor in cell density-dependent growth in cervical cancers and leukemias. Cancer Res 2001, 61:6281-6289

12. Monroy-García A, Ortíz-Navarrete V, Mora-García M, Flores-Borja F, Diaz-Quiñones A, Isibasi-Araujo A, Trejo-Becerril C, Chacón-Salinas R, Hernández-Montes J, Granados Arreola J, de Leo C and WeissSteider B Identification of peptides presented by HLA class I molecules on cervical cancer cells with HPV- 18 infection. Immunol Let 1999, 67:167-177

13. Cullen A., Reid R., Campion M. and Lorincz A Analysis of the physical state of different human papillomavirus DNAs in intraephitelial and invasive cervical neoplasia. J Virol | 99|, 65:606-612

14. Badaracco G, Venuti A, Sedati A and Marcante ML HPVI6 and HPV 18 in genital tumors: Significantly different levels of viral integration and correlation to tumor invasiveness. J Med Virol 2002, 67:574-82

15. Debiec-Rychter M, Zukowski K, Wang CY and Wen WN Chromosomal characterizations of human nasal and nasopharyngeal cells immortalized by human papillomavirus type 16 DNA. Cancer Genet Cytogenet 1991, 52:5 I-6I

16. Minoguchi S, Minoguchi M and Yoshimura A Differential control of the NIMA-related kinases, Nek6 and Nek7, by serum stimulation. Biochem Biophys Res Commun 2003, 301:899-906

17. Geisen C, Delius H, Lichter P and Kahn T A Transcribed human sequence related to the mouse $\mathrm{HCl}$ and the human papillomavirus type 18 E5 genes is located at chromosome $7 \mathrm{p} \mathrm{I} \mathrm{3-14.}$ Hum Mol Genet 1995, 4:1337-1345

18. Knuutila S, Aalto Y, Autio K, Bjorkqvist AM, El-Rifai W, Hemmer S, Huhta T, Kettunen E, Kiuru-Kuhlefelt S, Larramendy ML, Lushnikova T, Monni O, Pere H, Tapper J, Tarkkanen M, Varis A, Wasenius VM, Wolf $M$ and $Z$ hu $Y$ DNA copy number losses in human neoplasms. Am J Pathol 1999, I 55:683-694

19. Mazurenko N, Attaleb M, Gritsko T, Semjonova L, Pavlova L, Sakharova $\mathrm{O}$ and Kisseljov $\mathrm{F}$ High resolution mapping of chromosome 6 deletions in cervical cancer. Oncol Rep 1999, 6:859-863

20. Takekawa M, Posas F and Saito $\mathrm{H}$ A human homolog of the yeast Ssk2/Ssk22 MAP kinase kinase kinases, MTKI, mediates stress-induced activation of the $\mathrm{p} 38$ and JNK pathways. EMBO J 1997, 16:4973-4982

21. Wentzensen $N$, Ridder $R$, Klaes $R$, Vinokurova S, Schaefer $U$ and Doeberitz MK Characterization of viral-cellular fusion transcripts in a large series of HPV 16 and 18 positive anogenital lesions. Oncogene 2002, 21:419-426

22. Thein A, Trkova M, Fox M and Parrington J The application of comparative genomic hybridization to previously karyotyped cervical cancer cell lines. Cancer Genet Cytogenet 2000, I 1 6:59-65

23. Baykal C, Ayhan A, Al A, Yuce $K$ and Ayhan A Overexpression of the c-Met/HGF receptor and its prognostic significance in uterine cervix carcinomas. Gynecol Oncol 2003, 88:123-129

24. Imoto I, Tsuda H, Hirasawa A, Miura M, Sakamoto M, Hirohashi S and Inazawa J Expression of clAPI, a target for I Iq22 amplification, correlates with resistance of cervical cancers to radiotherapy. Cancer Res 2002, 62(I 7):4860-6

\section{Pre-publication history}

The pre-publication history for this paper can be accessed here:

http://www.biomedcentral.com/1471-2407/3/8/prepub 